\title{
EL INDIGENISMO NARRATIVO PERUANO
}

\author{
Tomás G. Escajadillo \\ Universidad Nacional Mayor de San Marcos
}

En mis estudios sobre el indigenismo peruano he planteado que éste se inicia con Cuentos andinos (1920), de Enrique López Albújar. Esta afirmación cuasará sorpresa para quien está acostumbrado a leer en las historias y panoramas generales de la literatura hispanoamericana que el indigenismo en Nuestra América se inicia con la novela Aves sin nido (1889), de Clorinda Matto de Turner.

Así planteadas las cosas, queda subrayada la hazaña de la novela Raza de bronce, de Alcides Arguedas, publicadas un año antes que el vigoroso libro de cuentos de López Albújar.

No me mueve ni me interesa ningún factor «nacionalista»; no porque doña Clorinda Matto de Turner sea peruana ocultaré mi discrepancia con la crítica nacional y continental que realza el valor de $A$ ves sin nido como novela que inicia el indigenismo en Latinoamérica, como no me mueve a conceptuar a Ciro Alegría y José María Arguedas las «cumbres» del indigenismo hispanoamericano el hecho de que ostenten la misma nacionalidad.

Postulo que es indispensable, antes de iniciar una discusión al respecto, precisar qué entendemos por indigenismo, y qué es indigenismo, a diferencia de obras de temática indígena o andina que no constituyen propiamente indigenismo. En 1971 sustenté una tesis doctoral titulada La narrativa indigenista: un planteamiento $y$ ocho incisiones. En aquel «planteamiento» ha quedado fijada la primera de mis reflexiones sobre el indigenismo narrativo en el Perú, sobre su inicio y —sobre todo- sobre su evolución.

Se suele considerar por el grueso de la crítica hispanoamericanista que basta el «famoso» requisito de que una literatura tenga un «sentimiento de reivindicación» hacia el indio para que se configure una literatura indigenista; de otro lado, como en el citado caso de Aves sin nido, se suelen considerar «indigenistas» numerosas obras que en rigor no lo son. En mis tesis de 1971 establecía como una estrategia útil hablar de «indianismo» al referirme a todo lo que no constituye «indigenismo». En ese estudio ya añejo se postuló claramente una delimitación 
del concepto de «indigenismo» narrativo como diferenciado de un «indianismo» singular; la delimitación de estos conceptos terminó por sugerirme un esquema de evolución del «indigenismo». Ello me ha llevado, en 1971 y en muchas oportunidades posteriores, a reflexionar repetidas veces respecto a dos «presencias» del «tema indígena» en la prosa de ficción peruana que, a mi entender, no son «indigenismo»; así, hablo de un «indianismo modernista» (Los hijos del sol (1921), de Abraham Valdelomar, o los «cuentos peruanos» de Ventura García Calderón, como los de La venganza del cóndor (1924), por ejemplo), y de un «indianismo romántico-realista-idealista» (Narciso Aréstegui, Clorinda Matto de Turner), algunos de cuyos frutos son el antecedente del «indigenismo» propiamente tal. Aves sin nido (1889) tiene, por tanto, en mis planteamientos, el valor (que no desestimo en absoluto) de novela precursora del indigenismo; no, pues, primera obra indigenista (o «muestra de la primera generación de los narradores indigenistas») sino antecedentes de tal movimiento o escuela.

De otro lado, la indagación en torno a los cambios, la transformación, la evolución del indigenismo, me ha llevado a un elemental esquema que proclama dos momentos fundamentales: el primero, que abarcaría a una mayoría de las obras del género, que prefiero denominar «indegenismo ortodoxo), y una segunda fase de evolución, para la cual empleo la denominación de «neo-indigenismo». Es por ello que en mis trabajos sobre el indigenismo peruano uso los términos «indianismo modernista», «indianismo romántico-realista-idealista», «indigenismo ortodoxo» y «neo-indigenismo»; ya no, pues, «indigenismo» a secas: términos al que se pretende conferir una «flexibilidad» o «elasticidad» tal que le permita referirse a obras tan obviamente disímiles entre sí como El Padre Horán (1848) y Los ríos profundos (1958); «El alma de la quena» (1917) y «La agonía de Rasu Nita» (1962); Aves sin nido (1889) y Todas las sangres (1964), La venganza del cóndor (1924) y La tumba del relámpago (1979).

Precisemos ahora nuestro concepto de «indigenismo», las condiciones que debe tener una obra para merecer tal calificación. Además del requisito de «sentimiento de reivindicación social» del que nos han hablado tantos estudiosos, pienso que una narrativa auténticamente indigenista debe tener dos cualidades más; lo que enuncio como «Superación de ciertos lastres del pasado, especialmente la visión romántica del mundo andino», y la que exige a una novela indigenista «Suficiente proximidad» en torno al mundo novelado, el indio y el Ande.

Veamos con algún detenimiento estos tres requisitos. En el Perú, José Carlos Mariátegui fue el ideólogo y promotor cultural que, a través de sus escritos y de su revista Amauta, mejor supo subrayar este pre-requisito del indigenismo. Maríategui, argumenta con brillo y lucidez que el indigensimo no es una simple escuela o movimiento literario, sino que está motivado por el referente del mundo real: el indigenismo nace como una necesidad político-cultural-social de tratar de solucionar lo que en tiempo de Mariátegui se llamaba «el problema del indio» (y que hoy en día alguna gente no sólo cree que no ha sido solucionado, sino que, por el contrario, en algunos aspectos ha empeorado). Mariátegui contrasta el indigenismo peruano con el «nativismo» o «criollismo» uruguayo: «En el Uruguay, la literatura nativista, nacida como en la Argentina, de la experiencia cosmopoli- 
ta, ha sido criollista, porque ahí la población tiene la unidad que a la nuestra le falta. El nativismo, en el Uruguay, por otra parte, aparece como un fenómeno esencialmente literario. No tiene, como el indigenismo en el Perú, una subconsciente inspiración política y económica» ${ }^{1}$. Esta idea es repetida con sintomática insitencia; demos un segundo ejemplo: «El «indigenismo» no es aquí un fenómeno esencialmente literario, como el «nativismo» en el Uruguay. Sus raíces se alimentan de otros humus históricos. Los «indigenistas» auténticos —que no deben ser confundidos con los que explotan temas indígenas por mero «exotismo» (léase Ventura García Calderón/TGE) — colaboran, conscientemente o no, en una obra política y económica de reivindicación —no de restauración ni resurrección» (p. 356; mi subrayado). Por ello es que Mariátegui ve el «indigenismo» como una entidad múltiple, heterogénea (en la medida que plantea problemas sociales, económicos y políticos junto con su asedio desde la perspectiva de la literatura o las artes plásticas) e interdisciplinaria: «El «indegenismo» de nuestra literatura actual no está desconectado de los demás aspectos nuevos de esta hora. El problema indígena, tan presente en la política, la economía y la sociología no puede estar ausente de la literatura y del arte» (p. 352).

En el campo de la historia de la literatura más reciente, nos parece suficiente documentar nuestros planteamientos con un juicio de Luis Alberto Sánchez, explícitamente basado en indagaciones previas de Concha Melendez ${ }^{2}$ y Aída Cometta Manzoni ${ }^{3}$ : «Así, pues, dice Sánchez, la novela india de «mera emoción exotista» será la que llamaremos «indianismo», y la de un «sentimiento de reivindicación social», «indigenismo»» ${ }^{4}$.

En nuestro concepto, sin embargo, si bien una narrativa que busque una «mera emoción exotista» constituye «indianismo» (Ventura García Calderón, por ejemplo), en cambio, no basta el «sentimiento de reivindicación social» para que una obra sea indigenista. Tomemos el importante ejemplo de Aves sin nido. La novela de la Matto de Turner es un libro en donde se percibe un fuerte «sentimiento de reivindicación social»y, sin embargo, sus indicios son tan borrosos («cuerpo de indio y alma de blanco», para utilizar una frase de Sánchez), su paisaje tan artificial y, además de ello, la novela muestra tantos elementos románticos (situaciones narrativas, tópicos temáticos y lenguaje exaltado y sentimentalista), que nos llevan al considerarla no la primera novela «indigenista» sino una de las últimas «indianistas»; es decir, novela donde confluyen muchos (demasiados para mi gusto) elementos de una tradición anterior del tratamiento del «tema indíge-

1 La presente y siguientes citas de los 7 ensayos de interpretación de la realidad peruana corresponden a la tercera edición de este libro capital (Lima, Empresa Editora Amauta, (Biblioteca Amauta), 1952); lo transcrito: p. 354.

2 Concha Meléndez: La novela indianista en Hispanoamérica (1832-1889). Madrid, Hernando, 1934; 2a ed.: Río Piedras, Ediciones de la Universidad de Puerto Rico, 1961 (Libro impreso en España).

3 Aída Cometta Manzoni: El indio en la novela de América. Buenos Aires, Editorial Futuro, (Colección Eurindia), 1961. (La misma autora había publicado antes: El indio en la poesía de América. Buenos Aires, Joaquín Torres, Editor, 1939).

4 Luis Alberto Sánchez: Proceso y contenido de la novela hispano-americana. Madrid, Editorial Gredos, Biblioteca Románica Hispánica, (estudios y Ensayos 11), 1953, p. 545. 
na», la tradición «romántica» (que precisamente ha sido muy bien documentada por Concha Meléndez), con los elementos «nuevos», los de denuncia de los abusos que se cometen contra el indio. Sin embargo, los «nuevos» elementos oscilan entre la mera «información», la «documentación» no dramatizada de un atropello típico (los préstamos forzosos, por ejemplo), y estos abusos teñidos por situaciones o lenguaje sentimentales (el abuso sexual de los curas serranos se entrelaza y termina confluyendo con la situación tópica archi-romántica de los hermanosamantes, amantes que - sin saberlo- son hermanos). En Aves sin nido subsisten, mezclados con los elementos de una escuela o movimiento del futuro, el «indigenismo», (como, por ejemplo, la presentación de una imperfecta muestra de la «trilogía embrutecedora» del indio, o la nefasta actuación de un cura serrano lujurioso); demasiados elementos de un tratamiento del «tema indígena» que pertenecían, en ese momento: 1889, al pasado: el tratamiento romántico, la novela idealista de exaltación romántica del indio.

En mi conceptualización del término «indigenismo» aplicado a la narrativa no basta, pues, el factor «sentimiento de reivindicación social». Hace falta, además, la superación de ciertos elementos o lastres del pasado: la visión romántica, la idealización romántica del mundo indio. Un tercer factor importante, muy difícil de especificar en abstracto, se refiere a lo que llamaré, a falta de otra denominación más precisa, «suficiente proximidad» en relación al mundo recreado: el indio y el Ande. Soy consciente de la imprecisión de esta terminología. La configuración de una «suficiente proximidad» en relación del mundo representado es, además, algo que sólo puede determinarse en el análisis de un texto específico, nunca antes, por lo menos no con razonable precisión. En la peligrosa evaluación de la dualidad lejanía/cercanía frente al mundo observado, debe determinarse el punto de quiebra que proporciona una «suficiente proximidad» del mundo recreado, lo cual, junto con los dos elementos ya señalados (superación de lastres románticos y «sentimiento de reivindicación social», aunque este último factor pueda no ser muy explícito o incluso se dé inconscientemente) produciría una obra auténticamente indigenista.

La primera obra narrativa peruana en la que se conjugan estos factores es, a mi entender, Cuentos andinos (1920), de Enrique López Albújar. Con ella se inicia, en mi esquema, lo que llamo el «indigenismo ortodoxo». López Albújar pudo así configurar por primera vez en nuestras letras (casi paralelamente a Raza de bronce (1919), del boliviano Alcides Arguedas) lo que, en acertada frase ha llamado Ciro Alegría «indios de carne y hueso» ${ }^{5}$. La hazaña de López Albújar fue la de romper con una larga tradición de indios borrosos, lejanos, excesivamente estilizados o idealizados, «poniendo en circulación literaria a indios de carne y hueso», en la afortunada expresión de Ciro Alegría, actor principal de la misma empresa literaria y humana, y cuya opinión resulta, por tanto, singularmente va-

5 Ciro Alegría: «A manera de prólogo». En: Memorias (de Enrique López Albújar). Lima, (Talleres Gráficos de P. L. Villanueva), 1963, p. 8. 
liosa. Pienso que Mariátegui (cuya omisión de Aves sin nido al estudiar el indigenismo me parece significativa) ${ }^{6}$ estaba en lo cierto cuando afirmaba en 1928:

No es aventurado, por tanto, la hipótesis de que el indio ha cambiado poco espiritualmente (...) el fondo oscuro de su alma casi no ha mudado. En las sierras abruptas, en las quebradas lontanas, a donde no ha llegado la ley del blanco, el indio guarda aún su ley ancestral.

El libro de Enrique López Albújar, «Cuentos andinos», es el primero que en nuestro tiempo explora estos caminos. Los «Cuentos andinos» aprehenden, en sus secos y duros dibujos, emociones sustantivas de la vida de la sierra, y nos presentan algunos escorzos del alma del indio (p. 360).

«Indios de carne y hueso»; «algunos escorzos del alma del indio»; o «alma y cuerpo de indio» (como dice Luis Alberto Sánchez): estas tres expresiones pueden servir para ilustrar lo que entiendo como «suficiente proximidad» en Cuentos andinos; en López Albújar se rompe claramente con el pasado, con la tradición romántico-idealista que tiene por tema al indio; existe un «sentimiento de reivindicación social» hacia el indio, aunque esto sea difícil de percibir conscientemente en su primer libro sobre el tema, a diferencia de lo que sucede en Nuevos cuentos andinos (1937), en donde sí se expresa con claridad dicho sentimiento; y hay lo que he llamado «suficiente proximidad» frente al objeto recreado (el Ande y su habitante).

Pero se trata de una (suficiente) proximidad relativa. Frente a los demás escritores que intentaron mostrar al indio antes que él (llámense Aréstegui o Matto), el «indio de López Albújar» se nos figura bien dibujado, vital, rebelde, convincente: «de carne y hueso»; sin embargo, frente al «indio de Ciro Alegría» esta «proximidad» nos parece ya inadecuada: sentimos que Ciro Alegría ha sabido acercarse al mundo andino, calar profundamente en la psicología de su habitante y, sobre todo, ha sabido darnos en El mundo es ancho y ajeno (1941), con la mayor fuerza y grandeza posibles, la dimensión épica de su tragedia colectiva.

$\mathrm{Y}$, sin embargo, al comparar «el indio de Alegría» con «el indio de Arguedas» podríamos afirmar que nadie como éste ha podido fundir en uno solo el «yo» desgarrado del narrador protagonista con el «ellos» (los indios). Lo cual nos lleva nuevamente a Mariátegui:

Y la mayor injusticia en que podría incurrir un crítico, sería cualquier apresurada condena de la literatura indigenista por su falta de autoctonismo integral o la presencia, más o menos acusada en sus obras, de elementos de artificio en la interpretación y en la expresión. La literatura indigenista no puede darnos una versión rigurosamente verista del indio. Tiene que idealizarlo y estilizarlo. Tampoco puede darnos su propia ánima. Es todavía una literatura de mestizos. Por ello se llama indigenista y no indígena. Una literatura indígena, si debe venir, vendrá a su tiempo. Cuando los propios indios estén en grado de producirla. (pp. 358-59; mi cursiva).

6 A diferencia de Francisco Carrillo (Clorinda Matto de Turner y su indigenismo literario. Lima, Ediciones de la Biblioteca Universitaria, 1967, p. 42), yo no pienso que sea una omisión inconsciente o un simple olvido el que Mariátegui excluyera de su «Proceso» a la literatura peruana a $A$ ves sin nido. Hay que considerar que Mariátegui se refirió en otros lugares con mucho respeto y consideración al sentido progresista de las luchas de doña Clorinda Matto de Turner. 
Esta cita ha devenido clásica, famosa. Son muchos los críticos que han subrayado su lucidez y clarividencia. Pero, mientras el ilustre profesor Agustín Cueva, del Ecuador, en un estudio de 1978, acota, al citar exactamente el mismo párrafo:

En esta perspectiva, la primera constatación que cabe hacer es la de que la literatura indigenista del Ecuador no logró rebasar, con ninguna de sus manifestaciones, el límite indicado por Mariátegui. Y es que tal vez sea el peruano José María Arguedas el único que hasta ahora ha superado esa frontera, de manera muy problemática y en la medida que él mismo era, culturalmente hablando, por lo menos mitad indio. No nos corresponde analizar aquí su obra sino sólo señalarla como un punto de referencia diferencial con el que cualquier cotejo valorativo resulta ilegítimo, puesto que ningún escritor ecuatoriano intentó abordar la cuestión indígena en un plano similar. El acercamiento al problema es tan distinto en obras como Huasipungo y Los ríos profundos, por ejemplo, que hasta da lugar a estructuras narrativas claramente divergentes: «realística» en el primer caso, tan lírico que llega a colindar, con la prosa poética en el segundo ${ }^{7}$.

Antonio Cornejo Polar, en una brillante colección de artículos, a partir de $1977^{8}$, y un breve libro-síntesis de $1980^{\circ}$, prefiere extraer de la misma cita de Mariátegui lo fundamental de su importante teoría del «indigenismo como literatura heterogénea». Ayudado por nuestra cita, Cornejo argumenta que en el indigenismo hay un mundo, el del indio, que es abordado por un escritor "de otro mundo», y que emplea una forma artística ajena al mundo cultural indígena, vale decir, el «género» novela, algo estrictamente perteneciente al mundo «occidental».

Séame permitido recordar los términos en los que al subrayar — por primera vez en la crítica literaria - la consignada - y famosa - cita de Mariátegui, comentaba: «¿Exageraríamos — decía en 1971- al afirmar que en estas palabras hay toda una tesis, o por lo menos una «hipótesis de trabajo» que permite una interpretación total, audaz y sugestiva, del proceso del indigenismo peruano? ¿podría decirse que Arguedas sería esa segunda (y final) fase, de la cual habló en 1928 Mariátegui, es decir una literatura no «indigenista» sino «indígena», realizada por un «propio indio»? Seamos más cautos. Mariátegui no proclamaba la necesidad de tal «literatura indígena»; dice textualmente «si debe venir»; no está seguro, pues, que ello sea conveniente. Luego, ¿hasta qué pronto se puede considerar a

7 Agustín Cueva: «En pos de la historicidad perdida (contribución al debate sobre la literatura indigenista del Ecuador)». En: Revista de Crítica literaria latinoamericana. Lima, año IV, Nos. 7-8, 1. y 2\% semestre de 1978, p. 32.

8 Antonio Cornejo Polar: «Para una interpretación de la novela indigenista». En: Casa de las Américas. La Habana, N. 100, enero-febrero de 1977, p. 40.

«El indigenismo y las literaturas heterogéneas: su doble estatuto socio-cultural». En: RCLL N . 7-8, op. cit., pp. 7-21.

«Sobre el modo de producción de la literatura indigenista». En: Homenaje a Jorge Basadre. Lima, Pontificia Universidad Católica, Vol II, 1978, pp. 51-59.

«La novela indigenista: un género contradictorio». En: Texto crítico. Xapala, Veracruz, (México), N. V, 14, junio-septiembre de 1979, pp. 58-70.

«La novela indigenista: una desgarrada conciencia de la historia». En: Lexis. Lima, Pontificia Universidad Católica, IV, № 1, julio de 1980.

9 (A. C. P.): Literatura y Sociedad en el Perú: La novela indigenista. Lima, Lasontay, (Biblioteca de Cultura Andina), 1980. 
José María Arguedas «uno de los propios indios?» Por supuesto: sabemos que los amó, siendo niño, sin límite alguno; que odió ferozmente a sus enemigos; que quiso no ser un «mak'tillo falsificado», «hijo de misti/blanco, abogau»; que se refugió en comunidades, en la ternura de una segunda madre, cocinera india; que hizo todo lo posible por ser, plenamente, «uno de ellos» (por convertirse en un comunero sanjuan, wanaku, ak'ola («Agua»), 1935, su primer relato; k'ayau, pichk'anchuri, chaupi, k'ollana (Yawar fiesta, 1941); lahuaymarca (Todas las sangres (1964); que hubiera querido incluso ser un humillado colono, como los de la hacienda Patibamba en Los ríos profundos, 1958) o convertirse en cualquiera de esas patéticas figuras, mitad caricaturas, remedo de seres humanos, mitad santos o locos o descendientes de un Dios andino que pueblan el miserable puerto de Chimbote en El zorro de arriba y el zorro de abajo (1971). Sabemos que aprendió a nombrar las cosas que lo rodeaban, a entender el mundo con la «dulce lengua» de los indios; que gran parte de su valiosísima obra narrativa debe entenderse como una «pelea infernal» con el idioma, como un esfuerzo gigantesco por traducir todo un mundo (hombres, ríos, zumbayllus, montañas, flores) al castellano, por traducir toda una concepción del mundo (la ternura de los indios, el amor por los animales, la chiririnka, mosca azul que antecede a la muerte, el yamani tutelar, las piedras incaicas que hablan y se mueven) del habitante andino, que él aprendió en quechua, al castellano, idioma en que ha escrito sus cuentos y novelas. ¿Pero se puede decir que Arguedas sea un «indio»? ¿Acaso el solo hecho de que haya podido escribir (no ya algunas de las novelas más hermosas y significativas de América Hispana, sino el simple hecho de poder escribir correctamente el castellano) no lo separa, inevitablemente, de los «propios indios»? Esa separación ha sido, precisamente, uno de los «leit motivs» de toda su obra, una de las ondas que estremece toda su narrativa. Recordemos la primera página de esa temprana pequeña obra maestra que es «Warma Kuyay», uno de los relatos de su primer libro (Agua, 1935): «Se agarraron (los indios) de las manos y empezaron a bailar en ronda, con la musiquita de Julio el charanguero. Se volteaban a ratos, para mirarme, y reían. Yo me quedé fuera del círculo, avergonzado, vencido para siempre» ${ }^{10}$. (pp. 14-15).

Sirva la oportunidad para poder afirmar lo siguiente: sea o no sea la narrativa de José María Arguedas la obra de un «indio», nunca se tuvo antes en las letras hispanoamericanas un acceso tan profundo al alma indígena, nunca antes se pudo fusionar o compenetrar tanto el «yo» del narrador con el «ellos» (los indios), nunca se recreó el universo andino tan radicalmente «desde dentro». Pero José María Arguedas no es un creador aislado. (En mi manera de entender su obra, incluso, tendría que hablarse de dos Arguedas; el de los libros iniciales y el autor de Los ríos profundos y «La agonía de Rasu Niti» (1962), para no hablar del novelista que escribió El sexto, Todas las sangres y El zorro de arriba y el zorro de abajo, que pertenecería a una tercera fase o etapa). Arguedas trabaja dentro de una tradición «indigenista», dentro de una escuela o movimiento que

10 José María Arguedas: Amor mundo y todos los cuentos. Lima, Francisco Moncloa Editores, 1967 , p. 87. 
se transforma, que evoluciona, que pasa por un proceso de mutaciones o cambios (y precisamente Arguedas es el escritor que más contribuye a que dicha tradición evolucione). Y si Arguedas se encuentra en un extremo (pero dentro del movimiento), en el punto más interior o profundo, López Albújar está en otro extremo (pero, igualmente, dentro del movimiento), en el punto de mayor lejanía y menor compenetración con el universo andino. Si López Albújar apenas consigue brindarnos «algunos escorzos del alma indígena», Arguedas nos introduce a los recintos más íntimos de ella. López Albújar y José María Arguedas, constituyen, a mi manera de ver, los polos contrarios, los puntos extremos de una misma escuela: el indigenismo.

Pero ciertamente las diferencias tan saltantes que existen entre «sus» diversos mundos andinos nos hablan elocuentemente de la mutación, de la evolución de ese «indigenismo». Precisamente, pienso que uno de los rasgos que explica o caracteriza el proceso, la evolución del «indigenismo», es su cada vez mayor penetración en el «mundo total» del habitante andino. Desde este punto de vista López Albújar, Ciro Alegría y José María Arguedas significan tres niveles, cada vez más profundos, de compenetración con el indio, su alma, sus sueños, el drama de su explotación, la visión de su destino futuro. pero forman parte de la misma escuela, de la misma tradición. Esto podrá apreciarse con mayor utilidad cuando más adelante examinemos la posición de estos tres escritores en relación al mundo mágico-mítico-maravilloso de la cosmovisión andina.

Antes de analizar las transformaciones que explican, a mi juicio, el transito del «indigenismo ortodoxo» al «neo-indigenismo», sería conveniente recapitular y ampliar el comentario sobre los textos que no constituyen «indigenismo». Nuestra indagación en torno a las obras de «tema indígena» nos ha llevado, como hemos adelantado, a la formulación de dos «presencias» de dicho tema que no son indigenismo:

a) Un «Indianismo romántico-realista-idealista», cronológicamente anterior a formas «indigenistas», cuyos ejemplos más importantes son El Padre Horán (1848) y Aves sin nido (1889), novela esta última de mucho mayor interés y trascendencia, y a la que consideramos el antecedente más significativo del «indigenismo» propiamente dicho.

b) Un «Indianismo modernista», casi siempre anterior al «indigenismo», aunque algunas de sus muestras sean coetáneas a las primeras manifestaciones claramente «indigenistas». Este «indianismo modernista» se dio tanto en las suntuosas y esteticistas recreaciones del Imperio Incaico, como en los relatos de Valdelomar publicados póstumamente con el título de Los hijos del sol ${ }^{11}$ (1921), cuanto en relatos de ambientación andina en que el indio y su marco geográfico sirven propósitos de una búsqueda de lo «exótico», como en los llamados «cuentos pe-

11 Manuel Beltroy publicó los «cuentos incaicos» con el título de Los hijos del sol (Lima, Editorial Euforión, 1921) y, según, su testimonio, los relatos de este libro postumo de Abraham Valdelomar fueron escritos preferentemente a principios de la década anterior. Muy pocos de estos textos se publicaron en vida del autor. Los más conocidos, «El alma de las quenas» y «La arcilla del alfarero», se publicaron en 1917. (Respectivamente en La Prensa (8/3/17) y Variedades (26/5/17).). 
peruanos» de Ventura García Calderón, desde La venganza del cóndor (1924) en adelante, cuentos que posteriomente incluso, en su mayoría, fueron escritos en francés.

Apenas si vale la pena mencionar El Padre Horán (1848): la confusa y abigarrada novela folletinesca de Narciso Aréstegui es un muestrario extremo y abrumador de las mismas limitaciones o «herencias del pasado» que, menos marcadamente, existen en $A$ ves sin nido (1889), y que, insistimos, nos han llevado a no considerar «indigenista» a esta última novela, a pesar de numerosas y doctas críticas en contrario. Como ya hemos señalado estas características y/o defectos son: una excesiva lejanía frente al indio (a despecho de una actitud positiva con relación a él), la «idealización romántica» del mismo, la presencia de tópicos temáticos y formas de lenguaje exaltado que corresponden a una óptica claramente romántica, su edeblez ideológica, etc.

El caso de algunas manifestaciones del «indianismo modernista», en su modalidad de reconstrucción de un pasado imperial suntuoso, como en los «cuentos incaicos» de Valdelomar y algunos otros ejemplos ${ }^{12}$, no ofrece mayores problemas. La filiación modernista de este tipo de literatura nos parece evidente. Se trata de una modalidad del Modernismo en la que algunos de sus culturos tienden a sustituir la inclinación por lo «exótico geográfico» (e histórico, en algunos casos): China, Japón, la antigua Grecia, Versalles, etc., por una suerte de modalidad de lo «exótico histórico» de lo americano. En ambos casos se trata de una tendencia a la «fuga» de una realidad presente, la que rodeaba al artista modernista y que él, por lo general, reputaba fea, banal y poco interesante. Hay que nota, sin embargo, que también se da una preocupación «nativista» en algunos escritores del modernismo que intenta describir, cuidando siempre el lenguaje, el paisaje y el hombre americano de su día; a esta modalidad pertenece, a mi juicio, Ventura García Calderón, quien produce una suerte de «anti-indigenismo», en la medida que representa, por ejemplo, una actitud contraria al clásico «sentimiento de reivindicación social» hacia el indio.

Apoyemos nuestra argumentación con alguna caracterización del Modernismo. De la inmensa bibliografía sobre él, acudamos a la palabra señera e inicial de Max Henríquez Ureña:

Dentro del modernismo pueden apreciarse dos etapas: en la primera, el culto preciosista de la forma favorece el desarrollo de una voluntad de estilo que culmina en refinamiento artificioso y en inevitable amaneramiento. Se imponen los símbolos elegantes, como el cisne, el pavo real, el lis; se generalizan los temas desentrañados de civilizaciones exóticas o de épocas pretéritas; (...) No es que los modernistas desecharan del todo los motivos de inspiración más honda: las torturas del alma contemporánea encontramos siempre repercusiones intensas en esa literatura; y en cuanto a los temas americanos, raro era el poeta o escritor moder-

12 C. F., en especial: Augusto Morales: La justicia de Huayna Cápac. Valencia, Tipografía Hispano Americana, 1918?; y El pueblo del sol. Lima, Editorial Garcilaso, 1924, 2a ed. Lima, Imprenta Torres Aguirre, 1927; y también libros como: Francisco Loyaza: El inka piadoso y justiciero. Barcelona, Maucci, 1934; e «Into Illapa» (seud.): El fin del Tawantinsuyo. Novela histórica. Tomo I, (1946). 
nista, que los echara totalmente al olvido; pero un ansia de refinamiento, que a veces degeneraba en frivolidad, era lo que parecía dar a tónica del movimiento ${ }^{13}$. Mi cursiva.

Es claro que en estas caracterizaciones caen tanto Valdelomar como García Calderón. El primero «desentraña temas de civilizaciones (...) de épocas pretéritas», mientras que del segundo ciertamente se puede afirmar tiene «una voluntad de estilo que culmina en refinamiento artificioso y en inevitable amaneramiento» y que su «ansia de refinamiento a veces degeneraba en frivolidad».

En cuanto a Valdelomar, los tres críticos más solventes al respecto señalan claramente la filiación modernista de sus «cuentos incaicos». En el clásico libro Valdelomar: Signo (Lima, Sphinx, 1940) afirma Luis Fabio Xammar:

Yo creo que el elemento lejanía es fundamental en la creación Valdelomariana (...) Cuando Valdelomar traspone esta etapa de indecisión, y se percata que su decadentismo literario no está encaminado a perdurar, sustituye esta lejanía geográfica, por una lejanía temporal, por una devoción hacia el pasado, en el que le placen los elementos puramente espectaculares, que puede encontrar, en él. Mientras que a sus cuentos costeños va con criterio peruano; a sus cuentos incaicos va con criterio europeo, a explorar elementos pintorescos y acusadamente sensuales. (pp. 67-68). Mi cursiva.

Más tajantes aún son los dos estudiosos de Valdelomar más importantes en la actualidad. Armando Zubizarreta declara enfaticamente: «Los cuentos incaicos (...) representan una dirección modernista — de cepa romántica- empeñada en reconstruir, con lenguaje lujoso y melódico, el pasado incaico ${ }^{14}{ }^{14}$, señalando asimismo «la idealización imperial a que tienden estos relatos en su camino a la evasión» ${ }^{15}$. Igualmente claro es respecto, Luis Alberto Sánchez, al analizar los «cuentos incaicos» en su conocido libro Valdelomar o la belle époque ${ }^{16}$.

En cuanto a Ventura García Calderón —sobre quien he escrito un polémico «Proceso a Ventura García Calderón» ${ }^{17}$ baste decir ahora que, en tanto «modernista», no sólo se interesa en el indio exclusivamente como motivo «exótico» (pensando, sobre todo, en el público lector europeo al que van destinados sus textos $\left.{ }^{18}\right)$; hay algo más: García Calderón no sólo no adopta el «sentimiento de reivindicación social» hacia el indio - que habíamos reputado una de las tres condiciones esenciales para que se pueda hablar de «indigenismo», sino que asume lo

13 Max Henríquez Ureña: Breve historia del modernismo. México, Fondo de Cultura Económica, 1954; cito por la Segunda ed., idem, de 1962, p. 33.

14 Armando Zubizarreta: «Introducción» a Cuentos (de Abraham Valdelomar). Lima, Editorial Universo, (Colección de Autores Peruanos), s. f. (1969), p. 7.

15 Ibídem.

16 Luis Alberto Sánchez: Valdelomar o la belle époque. México, Fondo de Cultura Económica, (Colección Popular, 94), 1969; 2a ed. 1988.

17 «Proceso a Ventura García Calderón» es una de las «incisiones» de mi tesis de 1971 (pp. 90-116), luego publicada en mi libro Narradores peruanos del siglo XX. La Habana, Casa de las Américas, (Colección «Cuadernos CASA», 30), 1986, pp. 47-66.

18 Después de La venganza del cóndor (1924), Ventura García Calderón publicó «libros en francés para franceses», que sólo más tarde aparecieron en versiones castellanas. C. f. nota siguiente. 
que Mariátegui certera y duramente llamaba «el espíritu de casta de los «enconmenderos» coloniales» (p. 245), en la visión del mundo de Riva Agüero y su grupo, del cual Ventura García Calderón era conspicuo integrante. Es decir, en buena medida, el autor de La venganza del cóndor (1924) significa una suerte de negación de las esencias mismas del indigenismo. Sin embargo, muchos críticos sobre todo de generaciones pasadas - siguen usando el término «indigenismo» para todo tipo de «presencias» del «tema indígena» y así hacen de Ventura García Calderón un «indigenista» más; en cambio el veredicto de escritores y críticos más jóvenes es negativo en relación a este autor ${ }^{19}$, quizás uno de los escritores peruanos más promocionados en Europa en nuestro siglo ${ }^{20}$. Hoy en día ha acabado la «benevolencia» con Ventura García Calderón.

Pasemos ahora a explicar nuestros planteamientos en torno a las transformaciones que explican el proceso del indigenismo, es decir, el tránsito del «indigenismo ortodoxo» al «neo-indigenismo». Me voy a permitir que sea un colega quien sintetice mis planteamientos al respecto. En el excelente número monográfico que la Revista Iberoamericana dedica recientemente al indigenismo ${ }^{21}$, Antonio Cornejo Polar inicia su estudio ${ }^{22}$ de la siguiente manera: «En su tesis doctoral sobre la narrativa indigenista peruana, Tomás G. Escajadillo propuso periodizar en tres tramos el proceso de ese movimiento: indianismo, indigenismo ortodoxo y neoindigenismo. Actuante a partir de la década de los cincuenta, o en todo caso después de la fecha en que aparecen las novelas que culminan y en cierto modo agotan la capacidad creativa del indigenismo ortodoxo (El mundo es ancho y ajeno y Yawar fiesta, ambas de 1941), el neoindigenismo se definiría por la convergencia de los siguientes caracteres:

a) El empleo de la perspectiva del realismo mágico, que permite revelar las dimensiones míticas del universo indígena sin aislarlas de la realidad, con lo que obtiene imágenes más profundas y certeras de ese universo.

b) La intensificación del lirismo como categoría integrada al relato.

c) La ampliación, complejización y perfeccionamiento del arsenal técnico de la narrativa mediante un proceso de experimentación que supera los logros alcanzados por el indigenismo ortodoxo.

19 En el volumen que recoge las astas del muy importante Primer encuentro de narradores peruanos (Lima, Casa de Cultura del Perú, 1969), por ejemplo, se consigna el «voto en contra» respecto a Ventura García Calderón formulado por Sebastián Salazar Bondy y José Miguel Oviedo, principalmente, pero respaldados por muchos de los asistentes: los maestros Alegría y Arguedas y los «neoindigenistas» más brillantes en ese momento, Carlos Eduardo Zavaleta y Eleodoro Vargas Vicuña. Mario Vargas Llosa también ha escrito juicios condenatorios respecto del autor de Danger de mort (1926), Couleur de sang (1931) y Le sang plus vite (1936).

20 En 1933 muy distinguidos intelectuales pidieron se otorgara el Premio Nobel a Ventura García Calderón, en ese entonces residiendo en dicha ciudad con un cargo diplomático. El pedido de los escritores franceses tuvo un enorme respaldo por parte de los intelectuales del Perú.

21 Revista Iberoamericana № 127. Número especial dedicado a la proyección de lo indígena en las literaturas de la América Hispana. Pittsburgh, (USA), (Impreso en España), L, NNo 127, abril-junio de 1984.

22 Antonio Cornejo Polar: «Sobre el «neoindigenismo» y las novelas de Manuel Scorza, loc. cit., pp. 549-57. En adelante sólo daremos la paginación. 
d) El crecimiento del espacio de la representación narrativa en consonancia con las transformaciones reales de la problemática indigena, cada vez menos independiente de lo que sucede a la sociedad nacional como conjunto». (p. 549).

A lo cual el profesor Cornejo Polar añade: «Esta última característica, pero no sólo ella, hace necesario debatir si el neoindigenismo es una transformación orgánica de la tradición anterior o, más bien, su cancelación. [Se refiere Cornejo casi exclusivamente a la «ampliación» o apartado «d)» de mis planteamientos]. Escajadillo opta por lo primero, pero establece como campo propio del indigenismo una delgada franja en la que solamente aparecen insertos los relatos del «segundo Arguedas», el de Los ríos profundos y «La agonía de Rasu Niti», todos los cuentos de Eleodoro Vargas Vicuña y algunos de Carlos Eduardo Zavaleta ${ }^{23}$. Los dos últimos pertenecen a la llamada «generación del 50»». (pp. 549-50).

Antes de consignar el valioso aporte de Cornejo Polar a la elucidación de este problema, diremos que, después de 1971, en que fue sustentada mi tesis, han surgido una decena de narradores «neo-indigenistas», que amplían la «delgada franja» de narradores «neo-indigenistas»; narradores de significación notable, detrás de los cuales muchos otros escritores jóvenes están practicando en nuestros días «neo-indigenismo» en el Perú. Así, a los tres escritores —encabezados por el «segundo Arguedas»— que yo veía en 1971, hay que agregar, además del importantísimo «neo-indigenismo» Manuel Scorza, que motiva las reflesions de Cornejo Polar, una decena más, como tendremos oportunidad de esclarecer en la parte final de este texto.

Pero sigamos con el profesor Cornejo Polar (ex Rector de mi Universidad, la Nacional Mayor de San Marcos, la Primera de América). «La caracterización que propone Escajadillo - agrega - es correcta; sin embargo, sería necesaria articularla con una concepción general del indigenismo que no se limitara a definirlo por su referente (el mundo indígena) y por su intencionalidad (una literatura de denuncia y reivindicación), sino que pudiera observar prioritariamente su proceso de producción». (p. 550).

A lo que, acto seguido, el profesor Cornejo enuncia su ya mencionada teoría del indigenismo como una «literatura heterogénea»:

Esta perspectiva permite ver lo que es esencial en el indigenismo: su heterogeneidad conflictiva, que es el resultado inevitable de una operación literaria que pone en relación asimétrica dos universos socioculturales distintos y opuestos, uno de los cuales es el indígena (al que corresponde la instancia referencial), mientras que el otro (del que depende las instancias productivas, textuales y de recepción) está situado en el sector más moderno y occidentalizado de la sociedad peruana. Esta contradicción interna reproduce la contradicción básica de los países andinos. (p. 550).

Séame permitido, por razones de espacio, no comentar ni evaluar esta teoría del indigenismo como una «literatura heterogénea»; me limitaré a lo ya dicho en

23 En este punto es que Cornejo Polar cita mi tesis doctoral de 1971. 
otras oportunidades ${ }^{24}$; los trabajos al respecto de Cornejo (consignados en las citas 8. y 9. del presente texto) constituyen, junto con los escritos del desaparecido profesor Angel Rama, las contribuciones teóricas más significativas de nuestros tiempos sobre el indigenismo narrativo hispanoamericano.

Intentemos ampliar aunque sea someramente nuestro esquema de la evolución de un «indigenismo ortodoxo» hacia un «neo-indigenismo». El apartado a), con palabras similares a las de Cornejo, podría enunciarse como «la utilización, en forma plena, de las posibilidades artísticas que ofrece el «realismo maǵico» o lo «real maravilloso» para la develación de zonas antes inéditas del universo mítico del hombre andino». En el «indigenismo ortodoxo», cuando se ofrecen estratos de la concepción «mágica» del universo por parte del indio, ello se presenta como algo «distinto» de la realidad. Es decir, se percibe todavía la fractura, el deslinde, entre los campos rigurosamente diferentes de lo «real-mágico» y lo «real-real»; no hay todavía una fusión plena de los dos estratos; López Albújar nos habla de «todo ese cúmulo de irracionales con que parece venir el indio al mundo» ${ }^{25}$; Rosendo Maqui piensa — nos informa el narrador omnisciente de $E l$ mundo es ancho y ajeno- que quizás sus antecesores sean cóndores; por el contrario, para el Ernesto de Los Ríos profundos las piedras del Cuzco se mueven y hablan al corazón; el Wamani («Dios montaña que se presenta en figura de cóndor») pasa de los hombros del dansak' Rasu Niti a los de su discípulo Atok'sayku cuando finalmente viene la chiririnka, la mosca azul que anuncia la muerte. Los indigenistas «ortodoxos», por el contrario, adoptan casi invariablemente una de dos actitudes. Aquéllos que, como López Albújar, se sienten muy lejanos del indio, y no entienden su estrato mágico y por tanto lo condenan:

Y junto con esta superstición, había conservado incólume cien más; todas referentes al culto de los cerros, quebradas, manantiales y apachetas: todas las prácticas de una liturgia primitiva, mezcla de bellaquería, credulidad y libertinaje, inventadas como para gente de apetitos bajos y fáciles y de imaginación infantil (p. 73).

O aquellos, como Ciro Alegría, que a través de la ilimitada voz del narrador omnisciente adoptan una actitud de «yo no opino» frente a la presencia de lo «mágico», una actitud que, en todo caso, nos distancia de ese estrato, que aparece así claramente señalado como una «creencia de indios» que podemos contemplar con o sin una sonrisa de benévola tolerancia, pero algo rigurosamente separado de lo que «nosotros» (los lectores y el narrador omnisciente) consideramos «la realidad».

No debiéramos, quizás, limitar el tratamiento que de la esfera de lo mágico, del estrato de lo mítico, hacen los «indigenistas ortodoxos», a esta dos maneras anotadas. Digamos sí en forma categórica que, sea cual fuere el procedimiento

24 Por ejemplo en: (TGE): «El indigenismo (no) ha muerto: ¡Viva el indigenismo!». En hueso húmero. Lima, № 5-6, abril-septiembre de 1980, pp. 155-65.

25 Enrique López Albújar: Cuentos Andinos (1920). Cito por: cuarta edición. Lima, Libreríaeditorial Juan Mejía Baca, 1965. (Libro impreso en la Argentina). En adelante daremos sólo la paginación de esta edición. 
adoptado, en las obras del «indigenismo ortodoxo» siempre podremos distinguir y diferenciar el estrato de lo «mágico» del estrato de «la realidad»; aunque intenten presentarse juntos, siempre veremos la «costura» que une (o separa) el estrato de lo «real maravilloso» del estrato de lo «real-real». El «realismo mágico», que implica una «aceptación» u «adopción» del estrato de lo mágico-mítico-religioso (en cualquier tipo de combinaciones) como algo que se da en el mundo» con la misma naturalidad que los «fenómenos naturales», sea a través del lente del narrador omnisciente o mediante el punto de vista de un personaje, brinda inmensas y nuevas posibilidades de una penetración más profunda y auténtica en el horizonte del habitante andino, para quien, precisamente, la «realidad» es distinta a la de un lector «occidental»: para él la «realidad», además de ríos, montañas, árboles y toros, diríamos «normales», está compuesta por wamanis, por jircas que fueron guerreros, aukis tutelares que intervienen en el destino humano; ríos que hablan al corazón, que traen mensajes de lejanas tierras; toros que son dioses, como el Misitu, sin dejar de ser toros; árboles que retienen, a través de los tiempos, un mensaje, que saben y ven y sienten y sufren.

Nadie ha sabido cantar «la descripción del llanto y la mágica maravilla de ríos y montañas» ${ }^{26}$ como José María Arguedas; algunos de los más jóvenes e inquietos cultores — comenzando por Eleodoro Vargas Vicuña y Zavaleta y siguiendo con muchos más - aprendieron de Los ríos profundos la aplicación al «indigenismo» de la manera nueva de ver y entender el mundo que significa el «realismo mágico». Debe observarse que, en sentido estricto, Vargas Vicuña y Zavaleta antecedieron cronológicamente al maestro Arguedas en la producción de narrativa «neo-indigenista» ${ }^{27}$. Apoyemos nuestra argumentación con dos referencias pertinentes. En la tercera edición de su muy influyente Historia de la novela hispanoamericana formula el profesor Fernando Alegría el siguiente juicio: «Arguedas es el representante máximo del nuevo realismo maǵico hispanoamericano» 28 . Anteriormente, en una entrevista de 1965, Arguedas había situado sus últimas obras dentro del «realismo mágico» ${ }^{29}$.

Otra forma colindante de «realismo mágico» es la que practica Manuel Scorza, en su importantísima pentalogía La guerra silenciosa, desde Redoble por Rancas (Barcelona, Planeta, 1971) hasta La tumba del relámpago (México, Siglo XXI, 1979), un «realismo mágico» más próximo a Macondo - pero no un Macondo de «copia y calco» sino uno de «creación heróica», como diría Mariátegui-: los caballos hablan, los hombres son invisibles o nunca duermen, los ríos y lagos sus-

26 Son palabras del propio Arguedas, consignadas —en términos idénticos - en dos entrevistas de 1965, la que yo le hiciera para la revista Cultura y Pueblo (Año II, N. 7-8) y la realizada por R. (aúl) V. (argas), para el diario Expreso (25 y 26 de marzo).

27 Nahuín, de Vargas Vicuña, es de 1953; Zavaleta publicó antes de Los ríos prófundos, La batalla y otros cuentos (Lima, 1954), El Cristo Villenas (México, 1955) y Los Ingar (Lima, 1955).

28 Fernando Alegría: Historia de la novela hispanoamericana. Tercera Edición. México, Ediciones de Andrea, 1966, p. 273.

29 C. f. Tomás G. Escajadillo; «Entrevista a José María Arguedas». En: Cultura y Pueblo. Lima, Casa de la Cultura del Perú, Año II, № 7-8, julio-diciembre de 1965, p. 23. (Es el texto citado en la nota 26). 
penden su curso, la gente vive en el fondo de los lagos, arcángeles se presentan en la Sierra Central del Perú, etc. El mundo de Scorza, a diferencia del de Arguedas es más mestizo que propiamente indio y en él la fantasía pura, ma=condiana, se entrelaza con la concepción mágico-religiosa que el indígena tiene de la realidad.

la segunda transformación hacia el «neo-indigenismo» había quedado enunciado como «la intensificación del lirismo como categoría integrada al relato», al punto que una denominación como «novela poemática» pueda resultar aceptable para una obra «indigenista». Esta mayor presencia de una prosa poemática - cuyos primeros frutos notables son Nahuín (1953) y Taita Cristo (1964) de Eleodoro Vargas Vicuña, Los ríos profundos (1958) y «El Cristo Villenas» (1955) y Los Ingar (1955), de Zavaleta - se presenta con frecuencia asociada a la utilización de la narración en primera persona, que es más bien inusual en la tradición del «indigenismo ortodoxo». Sin embargo, esta última característica necesitaría, pienso yo, un estudio amplio en el contexto global de «los dos indigenismos», para que pueda señalarse enfaticamente como un rasgo específico que ayude a explicar el tránsito del «indigenismo ortodoxo» o tradicional al «neo-indigenismo».

Hablamos de intensificación, no de aparición del indigenismo. A este respecto un juicio del profesor Juan Loveluck, aunque genéricamente correcto, puede resultar distorsionador:

Unas palabras finales acerca de la vigencia de algunos «ismos». Caducado el modernismo (...) otros «ismos» señalan ya su agotamiento. Así, el indigenismo documental y denunciatorio que puede decirse tuvo sus últimos capítulos de grandeza en las tres novelas de Alegría. Pero como tampoco la situación del indio ha mejorado, es propio que su presencia no desaparezca de nuestras letras. El, como personaje y problema, es una «constante». Solo que, agotado el molde viejo, esa «constante» ha necesitado otro odre: el neoindigenismo de cuño poético, que hallamos, por ejemplo, en las obras de José María Arguedas -piénsese, sobre todo (...) en Los ríos profundos. ${ }^{30}$.

Puntualicemos que nosotros hacemos del «cuño poético» no el elemento único sino uno de cuatro que explican la insurgencia del «neo-indigenismo». También discrepamos - a pesar del acierto genérico del planteamiento de Loveluck- en considerar que lo «documental y denunciatorio» haya desaparecido en las ficciones «neo-indigenistas» - piénsese en la monumental «denuncia» que implica la pentalogía La guerra silenciosa de Scorza, paro no seguir hablando de Arguedas-; finalmente es un error pensar que «lo poético» no existía en el indigenismo tradicional. Precisamente los ejemplos que utiliza Loveluck son desacertados ${ }^{31}$, puesto que justamente las novelas de Ciro Alegría —el más importante cultor del «indigenismo» tradicional - tienen un gran aliento poético, especialmente la primera,

30 Juan Loveluck: «Nota preliminar» al capítulo de «Ciclos...« de su antología de textos críticos La novela hispanoamericana. Santiago de Chile, Universidad de Concepción/Editorial Universitaria, 1963, p. 156.

31 Son desacertados porque Los ríos profundos es una novela que no ha dejado de ser «documental y denunciatoria»; igualmente, en las novelas de Alegría se encuentra ya el «cuño poético». C. f. nota 32 . 
el comienzo de Los perros hambrientos y muchos pasajes de su tercera y consagratoria novela. Se trata, pues, de «intensificación» no de la «aparición» del aliento poético. Recordemos a este respecto que el ilustre crítico chileno Fernando Alegría ha subrayado el aliento poético del autor de La serpiente de oro - contraponiéndolo al «realismo descarnado de los ecuatorianos»- en estos términos:

Frente al realismo descarnado de los ecuatorianos, la primera novela de Ciro Alegría, La serpiente de oro, sorprendió por su placidez lírica, su recatado sentimentalismo y su deliberada sobriedad (...) En un capítulo memorable (de Los perros hambrientos), en que intervienen la pastora Antuca, su ganado y sus perros, Ciro Alegría consigue una perfecta identificación del ser humano con el paisaje, un equilibrio de valores pictóricos y psicológicos que alza la narración a un plano de clásica belleza. En su lenguaje se acentúa la tendencia lírica (...) Ciro Alegría es, fundamentalmente, un poeta que escribe en prosa. De ahí los momentos de extraordinario lirismo que se advierten en su estilo ${ }^{32}$.

En tiempos posteriores algunos notables y jóvenes «neo-indigenistas» pongamos por caso Hildebrando Pérez Huarancca en su único libro Los ilegítimos (Lima, 1980), Félix Huamán Cabrera en sus últimos libros de fines de los 70 y comienzos de nuestra década- son claramente tributarios de la prosa poemática de Vargas Vicuña, de su esmerado trabajo con el lenguaje. Y otro escritor importante, Edgardo Rivera Martínez, ha sabido cincelar una muy personal prosa poemática, especialmente en el marco y la estructura totales del relato, tal como puede verse por ejemplo en su último - y laureado- libro Angel de Ocongate y otros cuentos (Lima, PEISA, 1986).

La tercera transformación que explica el surgimiento del «neoindigenismo», enunciada como «la ampliación, complejización y perfeccionamiento del arsenal técnico de la narrativa mediante un proceso de experimentación que supera los logros alcanzados por el indigenismo ortodoxo», es un asunto que merece un profundo replanteamiento desde 1971. En la tesis doctoral de ese año, sólo pude afirmar que esta transformación se había producido en el «segundo Arguedas» y en Vargas Vicuña y Zavaleta. Asimismo — subrayando la necesidad de iniciar trabajos serios en textos específicos- pensaba que una transformación radical a este respecto podría de terminar una «cancelación» del neo-indigenismo. La realidad de estos últimos veinte años me convence que ello no se ha producido.

En un estudio sobre los narradores «neo-indigenistas» posteriores a 1971 que, junto con el «planteamiento general» de mi tesis de ese año conforma el libro actualmente en prensa con el título de La narrativa indigenista: dos estudiosexamino la obra de dos grupos de escritores; el primero, y más importante, integrado por Manuel Scorza, Carlos Eduardo Zavaleta (en la continuación de su obra posterior a 1971), Marcos Yauri Montero, y Edgardo Rivera Martínez; y el segundo compuesto por narradores más jóvenes, Félix Huamán Cabrera, Hildebrando Pérez Huarancca, Víctor Zavala Cataño y Oscar Colchado Lucio. Pues bien,

32 Fernando Alegría: Historia de la novela Hispanoamericana, op.cit. (en la nota 28.), pp. 269-71. 
en todos estos escritores se da, sin que salgan del «neo-indigenismo», la complejización técnica de la que estamos hablando. El menos «renovador», el que emplea —en el cuento- moldes y estructuras más «clásicos», menos experimentales, es Rivera Martínez, pero ello se debe a una «poética» muy personal, no al desconocimiento de las complejas estructuras del cuento y la novela, pues su autor fue precisamente profesor de teoría de la novela por mucho tiempo en la Universidad N. Mayor de San Marcos.

Esta arquitectura se da tanto en la novela como en el cuento. De ello es muestra la pentalogía La guerra silenciosa, las novelas de este período de Zavaleta, Los aprendices (1974) y Retratos turbios (1982) y las cuatro novelas posteriores a 1971 (antes de ello este autor no había podido superar módulos de «indigenismo ortodoxo») de Marcos Yauri Montero, En otoño, después de mil años (La Habana, Casa de las Américas, 1974), novela ganadora del Premio de ese año de dicha importante institución, María Colón (Lima, 1980); en las novelas posteriores Yauri está un tanto «de regreso《 de la muy compleja arquitectura anterior, Mañana volveré (1983) y, por el momento, Así que pasen los años (Lima, 1985).

En el cuento «neo-indigenista» se dan todos los recursos de la narrativa contemporánea. De los autores citados, Zavaleta está abandonado, como hemos explicado en más de una oportunidad, el furioso experimento faulkneriano de algunos de sus textos iniciales, adoptando en su madurez una suerte de objetivismo a lo Henry James ${ }^{33}$, mientras que Rivera Martínez ensaya formas de «la difícil facilidad», los moldes sencillos en apariencia que, sin embargo, conllevan un gran trabajo del autor. Ni Scorza ni Yauri han cultivado el cuento; Hildebrando Pérez, Víctor Zavala, Félix Huamán Cabrera y Oscar Colchado han escrito hermosos relatos andinos que son una demostración inobjetable de que la tradición indigenista puede compatibilizarse con una «puesta al día» que representa la utilización de los procedimientos más sofisticados de la narrativa actual. Indivualicemos este enunciado con el ejemplo del cuento que da título al libro de Colchado, «Cordillera negra», en el que la gesta histórica de Atusparia y el Uchcu Pedro —que ya diera muestras valiosas en el pasado como El Amauta Atusparia (1930), libro prologado y elogiado por Mariátegui- está vista en la primera persona de un combatiente partidario del lúcido pero sanguinario «Uchcu Pedro» - primera persona narrativa, que recordemos, habíamos indicado era muy inusual en el «indigenismo ortodoxo»-, relato en el cual se puede examinar con provecho los tres elementos caracterizadores del «neo-indigenismo» que hemos analizado. Como dijéramos en 1971, «el estudio de las técnicas de Zavaleta de relatos de ambientación andina nos revela el tipo de «salidas» que tiene el «indigenismo ortodoxo», el tipo de innovaciones, experimentaciones y hallazgos que permiten hacer, en la actualidad, un «neo-indigenismo» que supere las limitaciones de la escuela tradicional, y que siga significando, para escritores de esta segunda mitad del siglo veinte, una tendencia (...) válida y todavía vital e importante». (p. 34).

33 Ver, por ejemplo, el estudio/testimonio de Zavaleta titulado: «Narradores peruanos: la generación de los cincuenta. Un testimonio». En: Cuadernos Hispanoamericanos. Madrid, № 302, agosto de 1975. (Hay separata: pp. 1-10). 
La cuarta y última transformación del indigenismo rezaba: «El crecimiento del espacio de la representación narrativa en consonancia con las transformaciones reales de la problemática indígena, cada vez menos independiente de lo que sucede a la sociedad nacional como conjunto», a lo que el profesor Cornejo Polar añadía: «Esta última característica, pero no sólo ella, hace necesario debatir si el neoindigenismo es una transformación orgánica de la tradición anterior o, más bien, su cancelación» ${ }^{34}$. Como bien apunta Cornejo Polar, en 1971 yo me pronunciaba por la interpretación de que una novela como Todas las sangres (1964) implicaba más que una «ampliación» una «cancelación» del indigenismo. Démosle, sin embargo, una nueva «vuelta de tuerca» al asunto. Como decía yo en 1971: «Esta cuarta «transformación debemos sopesarla con cuidado. Está pensada, además no en abstracto, sino en función de una obra concreta, Todas las sangres. No hay ninguna duda de que esta novela significa una transformación en la captación del «problema indígena» en el sentido de una «ampliación» tal como la que acabamos de describir; el verdadero problema es saber si una novela como Todas las sangres pertenece todavía al «neo-indigenismo»». (p. 24).

Claude Fell ha afirmado lo siguiente sobre Arguedas:

A diferencia de los escritores indigenistas tradicionales, Arguedas, no se sujeta a un conflicto limitado en el tiempo y el espacio: sus obras presentan esa versión global característica de la novela americana contemporánea ${ }^{35}$.

Por su parte el propio Arguedas ha sido un muy lúcido analista de Todas las sangres (a diferencia de su parquedad en el comentario sobre sus otros libros); consignemos siquiera tres citas: «En Todas las sangres aproveché cuanto he visto, sentido, comprendido, meditado a través de toda la vida» ${ }^{36}$; una segunda referencia muy escueta: «Me parece que en Todas las sangres hemos rebasado el tema estrictamente indigenista o tradicionalmente llamado indigenista» ${ }^{37}$.

Pero, en un texto que significa una deliberada última reflexión al respecto, plantea una doble posibilidad en relación a la validez del uso del término «indigenista» para Todas las sangres:

Finalmente, la narrativa peruana intenta, sobre las experiencias anteriores, abarcar todo el mundo humano del país en sus conflictos y tensiones interiores, tan complejos como su estructura social (...) En ese sentido la narrativa actual, que se inicia como indigenista, ha dejado de ser tal en cuanto abarca la descripción e interpretación del destino de la comunidad total del país, pero podría seguir siendo calificada de indigenista en tanto que continúa reafirmando los valores humanos excelsos de la población nativa ${ }^{38}$.

34 Antonio Cornejo Polar: «Sobre el «neo-indigenismo» y las novelas de Scorza», op. cit. (en las notas 21 y 22), p. 549.

35 Claude Fell: «José María Arguedas ou les amours et les haines du peuple andin». En: Le Monde, París, 7-8 de diciembre de 1969.

36 José María Arguedas: «Entrevista a José María Arguedas sobre Todas las sangres» concedida a Raúl Vargas, op. cit. (en la nota 26).

37 José María Arguedas: intervención en el Primer encuentro de narradores peruanos, op. cit. (en la nota 19), p. 240.

38 Jose María Arguedas: «Razón de ser del indigenismo en el Perú». En: Visión del Perú. Lima, N. 5 , junio de 1970 . 
Si en 1971 me inclinaba, no sin duda y vacilaciones ${ }^{39}$, por la primera alternativa, ahora no estoy tan convencido.

Las novelas de Zavaleta y Yauri que hemos citado, representan en las dos décadas posteriores a Todas las sangres la plasmación, si no de «novelas totales», por lo menos de novelas «bi-polares» ${ }^{40}$, en las que los protagonistas, en su mayoría no «indios» sino «serranos cultivados», deambulan tanto en Lima como en la mítica y, al mismo tiempo real zona del Callejón de Huaylas (región del Ande «Norte Chico»), de la que son oriundos ambos novelistas. En estas ficciones mayores se da lo que Arguedas enunciaba como la reafirmación de los valores humanos excelsos de la población nativa, lo que coincide plenamente con aseveraciones del otro maestro, Ciro Alegría, sobre el indigenismo: «el movimiento, la tendencia, persigue determinados fines, uno de ellos es el de la protesta y la lucha en favor de los indios, y otro es el de la valoración o revaloración intelectual del hombre indígena» ${ }^{41}$; añadiendo:

el indigenismo me parece que tiene dos aspectos bien claros: uno es el de la lucha y el de la reivindicación, y éste posiblemente pase, tarde o temprano, cuando llegue una nueva situación social; pero hay otros aspectos del indigenismo que es el que va a valorizar y ha estado descubriendo las calidades humanas del mundo indígena que han existido siempre y han existido heroicamente a través de siglos de opresión, porque el indio ha tratado de afirmar su cultura tradicional tercamente y la ha traído hasta nosotros en muchos aspectos ${ }^{42}$.

El indigenismo, o cierta forma de indigenismo, ha persistido y persistirá por mucho tiempo, afirman los dos máximos cultores de él, y si esto queda abudantemente documentado por la obra de los diez indigenistas posteriores a ellos, también, pienso yo, persiste la posibilidad de llamar «neo-indigenismo» a «novelas totales» como Todas las sangres o «bi-polares como Los aprendices y Retratos turbios, de Zavaleta, o las cuatro novelas citadas de Marcos Yauri; como nota anecdótica podría citarse la calificación del traductor al húngaro de En Otoño, después de mil años, László Scholz, para quien esta novela está «entre Arguedas y Cortázar».

Pienso que debe iniciarse una discusión, inexistente en la crítica peruana, acerca de las novelas «bi-polares», como las de Yauri y Zavaleta, así como en torno a la eventual filiación «neo-indigenista» de Todas las sangres, debate que increíblemente- casi no se ha planteado en la rica y numerosa bibliografía sobre Arguedas. Y así, pensando en el tópico del «ocaso del indigenismo», quisiera terminar estas palabras dirigiéndome a toda la suerte de críticos supuestamente «modernos» de la narrativa hispanoamericana — críticos casi invariablemente de fi-

39 Por ejemplo, en la paǵina 19 de mis tesis se lee: «... y el Arguedas de Los ríos profundos (1958), «La agonía de Rasu Niti» (y, quizás, aún el autor de Todas las sangres, 1964) que pertenece, a mi juicio, a las modalidades de un «neo-indigenismo»». (p. 19).

40 Conversaciones con Marcos Yauri Montero en enero de 1988.

41 Ciro Alegría: intervención en el Primer encuentro de narradores peruanos, op. cit. (en la nota 19), p. 248.

42 Loc. cit., p. 250. 
liación conservadora-, comenzando por los inefables críticos «oficiales», o por lo menos «anexos», del boom. Señores: «El indigenismo (no) ha muerto: ¡Viva el «neo-indigenismo!»».

\section{TEXTOS DEL AUTOR RELACIONADOS CON LA PRESENTE CONFERENCIA}

La narrativa indigenista: un planteamiento y ocho incisiones. Lima, Universidad Nacional Mayor de San Marcos. Tesis para optar el grado de Doctor. Programa Académico de Literaturas Hispánicas, 1971, 272 pp.

Seis de las ocho «incisiones» han sido publicadas, cuatro de ellas (las dos dedicadas a López Albújar, la relativa a Alegría y la concerniente a Arguedas), más de una vez.

La narrativa de López Albújar. Lima, Consejo Nacional de la Universidad Peruana (CONUP), 1972, $328 \mathrm{pp}$.

«Para leer a Mariátegui: 2 Tesis de los 7 Ensayos». En: 7 Ensayos/50 años en la historia. Lima, Empresa Editora Amauta, (Biblioteca Amauta), 1979, pp. 57-138.

«Ciro Alegría, José María Arguedas y el indigenismo de Mariátegui». En: Mariátegui y la literatura. Lima, Empresa Editora Amauta, (Biblioteca Amauta), 1980, pp. 61-106.

Alegría y El mundo es ancho y ajeno. Lima, Universidad Nacional Mayor de San Marcos, (Instituto de Investigaciones Humanísticas), 1983, XXVII + 197 pp.

Narradores peruanos del siglo XX. La Habana, Casa de las Américas, (Cuadernos CASA, 30), 1986, 195 pp.

La narrativa indigenista: dos estudios. Lima, Consejo Nacional de Ciencia y Tecnología (CONCYTEC): en prensa.

El relato indigenista en las páginas de «Amauta». Lima, Empresa Editora Amauta: en prensa. 